the vascular lumen (11). However, Walch et al. found that bone marrow-derived APCs such as dendritic cells were more effective in retaining $\mathrm{T}$ cells within the graft than were endothelial cells. Infiltration of nondonor-reactive $T$ cells into the transplant was enabled by cotransfer with donor-reactive T cells (8).

\section{Clinical implications}

Even perfect matching of major histocompatibility locus antigens between donor and recipient does not obviate the need for immunosuppressive therapy, because mismatches for the myriad of minor histocompatibility antigens can also lead to rejection. As blockade of chemokine/ chemokine receptor interactions will not block the initial stages of rejection, an alternative approach might be to treat with antibodies directed at the TCR complex.

Indeed, treatment with antibodies directed at a nonpolymorphic component of the TCR complex provides a wellappreciated therapeutic option to block the initial stages of the allograft response. Upon TCR activation, CD3 proteins polymerize with $\mathrm{T}$ cell antigen receptor protein (reviewed in ref. 12). Stimulation of the TCR complex by anti-CD3 leads to polymerization with the TCR, transiently activating $\mathrm{T}$ cells. Subsequently, $\mathrm{T}$ cell activation leads to an outpouring of proinflammatory cytokines, before the TCR complex is lost from the cell surface and immunosuppressive and even immune tolerance-promoting effects are obtained. Attempts to obviate these side effects by structural changes in the antibody have proven partially, but not totally, successful $(12,13)$. Further improvements in antibody design or adaptation of multiagent strategies that enable successful treatment with lower and safer doses of anti-CD3 are required. The work of Walch et al. (8) serves to refocus attention on the initiation of the allograft response from the chemokine/chemokine receptor pathway toward activation of the TCR complex. While paradigms may be dashed, this work elucidates the molecular basis of the initial stages of the allograft response. This newly obtained and more complete understanding of this process will have substantial implications for transplant medicine.

\section{Acknowledgments}

T.B. Strom is funded by grants awarded by the NIH (NIAID and NIDDK) and the Juvenile Diabetes Research Foundation.

Address correspondence to: Terry B. Strom, Beth Israel Deaconess Medical Center, 330 Brookline Avenue, E/CLS 608, Harvard Medical School, Boston, Massachusetts 02215, USA. Phone: 617.735.2880; Fax: 617.667.0923; E-mail: tstrom@bidmc. harvard.edu.

1. Springer TA. Traffic signals for lymphocyte recirculation and leukocyte emigration: the multistep paradigm. Cell. 1994;76(2):301-314.

2 . Bolt $\mathrm{S}$, et al. The generation of a humanized, non-mitogenic CD3 monoclonal antibody which retains in vitro immunosuppressive properties. Eur J Immunol. 1993;23(2):403-411.

3. Shulman $Z$, et al. Lymphocyte crawling and transendothelial migration require chemokine triggering of high-affinity LFA-1 integrin. Immunity. 2009; 30(3):384-396

4. Famulski KS, et al. Molecular phenotypes of acute kidney injury in kidney transplants. J Am Soc Nephrol. 2012;23(5):948-958.

5. Hancock WW, Gao W, Faia KL, Csizmadia V. Chemokines and their receptors in allograft rejection. Curr Opin Immunol. 2000;12(5):511-516.

6. Halloran PF, Fairchild RL. The puzzling role of CXCR3 and its ligands in organ allograft rejection. Am J Transplant. 2008;8(8):1578-1579.

7. Oberbarnscheidt $\mathrm{MH}$, et al. Memory T cells migrate to and reject vascularized cardiac allografts independent of the chemokine receptor CXCR3. Transplantation. 2011;91(8):827-832

8. Walch JM, et al. Cognate antigen directs $\mathrm{CD}^{+} \mathrm{T}$ cell migration to vascularized transplants. J Clin Invest. 2013;123(6):2663-2671.

9. Calderon B, Carrero JA, Miller MJ, Unanue ER. Cellular and molecular events in the localization of diabetogenic T cells to islets of Langerhans. Proc Natl Acad Sci U S A. 2011;108(4):1561-1566.

10. Calderon B, Carrero JA, Miller MJ, Unanue ER. Entry of diabetogenic $\mathrm{T}$ cells into islets induces changes that lead to amplification of the cellular response. Proc Natl Acad Sci U S A. 2011;108(4):1567-1572.

11. Pober JS, Tellides G. Participation of blood vessel cells in human adaptive immune responses. Trends Immunol. 2012;33(1):49-57.

12. Chatenoud L, Bluestone JA. CD3-specific antibodies: a portal to the treatment of autoimmunity. Nat Rev Immunol. 2007;7(8):622-632.

13. Keymeulen B, et al. Insulin needs after CD3-antibody therapy in new-onset type 1 diabetes. $N$ Engl J Med. 2005;352(25):2598-2608.

14. Abbas AK, Lichtman AH, Pober JS. Cellular and Molecular Immunology. 4th ed. Philadelphia, Pennsylvania, USA: Saunders; 2000.

\title{
Blazing a new TRAIL in hematopoietic cell transplantation
}

\author{
Nelson Chao \\ Duke University Medical Center, Bone Marrow Transplant Program, Durham, North Carolina, USA.
}

\begin{abstract}
There is a ying/yang to most biological therapies, and the balance of efficacy versus toxicity is delicate and sometimes difficult to achieve in favor of the patients. When the therapeutic window is wide, these therapies can be used in the majority of patients, but when the therapeutic window is narrow, the decision to proceed must be carefully balanced with a thoughtful risk-benefit analysis. In this issue of the JCI, Ghosh et al. tackle one of the major obstacles in hematopoietic cell transplantation (HCT) technology: balancing the beneficial antitumor effect with the harmful anti-host effect.
\end{abstract}

Conflict of interest: The author has declared that no conflict of interest exists.

Citation for this article: J Clin Invest. 2013; 123(6):2362-2363. doi:10.1172/JCI69909.
HCT describes the process of introducing new donor cells into a host, most often to treat hematological malignancy. The aim of treatment is to replace the dam- aged hematopoietic cells with normal stem cells, and requires the rebuilding of a new immune system, since the original needs to be destroyed to allow for donor engraftment. The new immune system can recognize virulent microbial agents, alloantigens, and tumor-specific antigens, leading to the beneficial graft-versus-tumor/leukemia (GVL) effect. On the other hand, donor $\mathrm{T}$ cell recognition of host antigens can result in graft-versushost disease (GVHD) (1). The occurrence of GVHD is the single greatest obstacle 


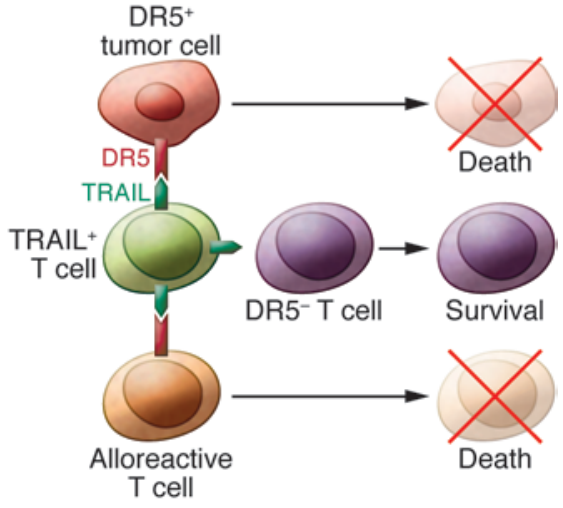

Figure 1

The promise of TRAIL+T cells in allo-HCT. The new sheriff (TRAIL + T cells) kill off DR5 ${ }^{+}$cells while sparing other $T$ cells, thus achieving the prevention of GVHD without loss of GVL.

to successful allogeneic stem cell transplantation, and the prevention of GVHD while preserving GVL is the holy grail of research in this field.

\section{Finding a balance}

Several early experimental models testing the potential for GVL by allogeneic cells failed because of the induction of GVHD (2, 3). As van Bekkum and de Vries described the state of the field in 1967, "It seems to be extremely difficult to induce that precise degree of graft versus host reactivity which will kill the leukaemic cells but which is at the same time mild enough to allow survival of the host" (4). By the mid-1970s, the clinical data demonstrated a lower leukemia relapse rate, and a significant survival advantage was associated with the development of GVHD (5). Thus, the understanding of the basic biology of $\mathrm{T}$ cells was still insufficient to balance GVHD and GVL.

\section{Following the TRAIL}

In this issue of the JCI, Ghosh et al. present tantalizing data to suggest that it may be possible to actually enhance GVL without increasing the risk of developing GVHD (6). This group previously demonstrated that TNF-related apoptosis-inducing ligand (TRAIL) is required for optimal GVL activity (7). In the current article, Ghosh et al. genetically engineered $\mathrm{T}$ cells to overexpress TRAIL and used these cells in adoptive transfer experiments (6). As expected, they observed that $\mathrm{TRAIL}^{+} \mathrm{T}$ cells were highly active in vitro and in vivo in a murine model. Surprisingly, however, they also found that these same cells led to reduced GVHD through the induction of apoptosis of alloreactive $\mathrm{T}$ cells (fratricide) and of host APCs, which upregulate the TRAIL receptor, death receptor 5 (DR5), following radiation (Figure 1). Further, using mice infected with lymphocytic choriomeningitis virus (LCMV), they found that $\mathrm{TRAIL}^{+} \mathrm{T}$ cells do not significantly impair antiviral responses. These data suggest that this population of $\mathrm{TRAIL}^{+}$ $\mathrm{T}$ cells is unique in that the cells can remove the $T$ cells that are responsible for GVHD through fratricide, but they do not kill off the T cells that convey protection from viral infections. Ghosh et al. further suggest that these $\mathrm{TRAIL}^{+} \mathrm{T}$ cells could be used "off the shelf" through a third-party donor and demonstrate that human $\mathrm{TRAIL}^{+} \mathrm{T}$ cells have enhanced cytotoxicity against several freshly isolated chronic lymphocytic leukemia cells.

\section{Conclusions and further directions}

Like all good articles, this work raises interesting questions. The first caveat to keep in mind is that these are data from murine models. While this is an important first step, human $\mathrm{T}$ cell biology may differ substantially, and more work will need to be done before this advance is translated to patient therapy.

It will be interesting and important to determine how these TRAIL ${ }^{+}$T cells traffic differently from other populations, since the luciferase images suggest that they do not pool in the gut at day 7 compared with wild-type, luciferase ${ }^{+}$, or $\mathrm{GFP}^{+}$ cells. It is possible that $\mathrm{TRAIL}^{+} \mathrm{T}$ cells are deleting the gut APCs, resulting in reduced $\mathrm{T}$ cell activation.

Furthermore, it is difficult to explain why these $\mathrm{TRAIL}^{+} \mathrm{T}$ cells do not suppress an antiviral response in a similar manner to the alloresponse. The authors suggest that this may be related to increased cytotoxicity of the TRAIL ${ }^{+} \mathrm{T}$ cells (6), but the molecular details of this remain to be elucidated. Last, it would be useful to know how long these cells would persist in vivo, as continued survival of $\mathrm{TRAIL}^{+} \mathrm{T}$ cells would result in suppressed immune responses if every activated $\mathrm{T}$ cell were eliminated.

We are now entering an exciting era in which adoptive cellular therapies are more commonplace, and the use of engineered $T$ cells is expanding. The approach described in this article of manipulating TRAIL expression before transplantation may provide a unique opportunity to target tumor cells without inducing GVHD. As mentioned above, cells overexpressing TRAIL could also be quite useful as an "off-the-shelf" third-party infusion following lymphodepletion in a patient, resulting in GVL activity during the lymphopenic period, followed by rejection of the allogeneic $\mathrm{TRAIL}^{+}$cells after recovery of host immunity. Indeed, the work by Ghosh et al. (6) suggests that TRAIL ${ }^{+} \mathrm{T}$ cells could exert their antitumor effects during this period of lymphodepletion, ridding the patient of the malignancy without altering their ability to fight viral infections. This manuscript advances the field of cellular therapy by documenting the potential of separating GVHD from GVL: the prevention of GVHD not only without loss of GVL, but actual enhancement of GVL.

Address correspondence to: Nelson Chao, Hematological Malignancies and Cellular Therapy/BMT, 2400 Pratt St., Suite 9100, Box 3961, Durham, North Carolina 27710, USA. Phone: 919.668.1010; Fax: 919.668.1091; E-mail: chao0002@ mc.duke.edu.

1. Sung AD, Chao NJ. Concise review: acute graft-versus-host disease: immunobiology, prevention, and treatment. Stem Cells Transl Med. 2013;2(1):25-32.

2. De Vries MJ, Vos O. Treatment of mouse lymphosarcoma by total-body $\mathrm{x}$-irradiation and by injection of bone marrow and lymph-node cells. J Natl Cancer Inst. 1958;21(6):1117-1129.

3. Mathe G, Bernard J. [Trial therapy, by $x$-irradiation followed by the administration of homologous bone marrow cells, of highly-advanced spontaneous leukemia in AK mice]. [French]. Bull Assoc Fr Etud Cancer. 1958;45(3):289-300.

4. van Bekkum DW, de Vries MJ. Radiation Chimaeras. London, United Kingdom: Logos Ltd; 1967.

5. Weiden PL, Sullivan KM, Flournoy N, Storb R, Thomas ED. Antileukemic effect of chronic graftversus-host disease: contribution to improved survival after allogeneic marrow transplantation. N Engl J Med. 1981;304(25):1529-1533.

6. Ghosh A, et al. Adoptively transferred TRAIL ${ }^{+}$ $\mathrm{T}$ cells suppress GVHD and augment antitumor activity. J Clin Invest. 2013;123(6):2654-2662.

7. Schmaltz C, et al. T cells require TRAIL for optimal graft-versus-tumor activity. Nat Med. 2002; 8(12):1433-1437. 